\title{
A Novel Miniaturized Polarization Independent Frequency Selective Surface with UWB Response
}

\author{
Sibel UNALDI ${ }^{1,2}$, Nigar Berna TESNELI ${ }^{1}$, Sibel CIMEN ${ }^{3}$ \\ ${ }^{1}$ Dept. of Electrical Electronics Engineering, Sakarya University, 54050 Serdivan Sakarya, Turkey \\ ${ }^{2}$ Dept. of Electrical Electronics Engineering, Bilecik Şeyh Edebali University, 11230 Bilecik, Turkey \\ ${ }^{3}$ Dept. of Electronics and Communications Engineering, Kocaeli University, 41380 Kocaeli, Turkey
}

sibel.unaldi@bilecik.edu.tr, btesneli@sakarya.edu.tr, sibelgunduz@kocaeli.edu.tr

Submitted April 9, 2018 / Accepted July 17, 2018

\begin{abstract}
This study presents a novel Frequency Selective Surface (FSS) design with angularly stable and polarization independent band-stop response. The presented FSS comprises miniaturized unit cells printed on two layers of the dielectric substrates. The $-3 d B$ bandwidth of proposed FSS is between $2.98 \mathrm{GHz}$ and $10.86 \mathrm{GHz}$ frequencies. The unit cell dimension is $0.064 \lambda \times 0.064 \lambda$ with the thickness of $0.02 \lambda$, where $\lambda$ is the wavelength of the lower operational frequency. The proposed FSS has angular stability up to $60^{\circ}$ for TE polarization. The designed FSS is simulated and analyzed by using the commercial software, CST Microwave Studio. The simulation results are verified by measurements carried on a fabricated prototype and a good agreement is achieved.
\end{abstract}

\section{Keywords}

Angularly stable, miniaturized, FSS, UWB

\section{Introduction}

Frequency Selective Surfaces (FSSs) are periodic arrays that can be configured by the periodic arrangement of metallic or slot which show transmission or reflection behaviors to both incidence angle and polarization of incident electromagnetic wave [1], [2]. FSS is widely studied in radomes, Radar Cross Section (RCS) reduction, gain enhancement of antennas, absorbers, wireless security, missiles, EM shielding, mobile and satellite communication [3-5]. Thus, FSS topics have been attracted researchers with its features of compact size and low cost. In 2002 the Federal Communications Commission (FCC) allocated the frequency band between $3.1 \mathrm{GHz}-10.6 \mathrm{GHz}$ for licensefree Ultra Wide Band (UWB) transmission [6]. Over recent decades license-free UWB frequency band technology has been used for exceeding limitation of traditional technologies [2]. Therefore, many FCC UWB components have been investigated intensely. UWB FSS components have been an attractive area for improving the design outputs and features. In the literature, there are some methods to design UWB FSS. In [3], [7] multiple resonant shapes, having different frequency response and printed on two surfaces of the single dielectric layer are studied. Multilayer UWB FSSs with metal plate are presented in [2], [8], [9]. UWB FSS design for antenna gain enhancement is explored in [4], [10]. A polarization independent UWB FSS which has the $14 \mathrm{~mm} \times 14 \mathrm{~mm}(0.18 \lambda \times 0.18 \lambda)$ dimension of the unit cell is reported in [11]. Polarization and angular independent compact band stop FSS design with the unit cell dimension of $8 \mathrm{~mm} \times 8 \mathrm{~mm}(0.187 \lambda \times 0.187 \lambda)$ is proposed in [12].

In this paper, a double layer band-stop UWB miniaturized FSS is introduced. The proposed UWB FSS has the advantage of the miniaturized size of the unit cell provided by the use of meandered lines. The overall dimension of the presented unit cell is compared with reported studies in the literature. In Tab. 2, comparison of the dimensions with frequency is given. Additionally, the proposed UWB FSS has the advantage of wide angular stability and polarization insensitivity features.

This study is organized as follows: In Sec. 2 unit cell configuration is described and design parameters are detailed. Simulation and measurement results of the proposed unit cell are illustrated in Sec. 3. Section 4 concluded the design with results.

\section{Design of Unit Cell}

In [1], to obtain the desired resonance frequency for band-stop filtering characteristic, a conventional square loop element has been introduced. Based on this study, many miniaturized FSS geometries are proposed in the literature. In [13], a miniaturized rotated cross dipole element is presented for X-band applications. In this study, a novel miniaturized FSS geometry is introduced. The geometry of the unit cell is depicted in Fig. 1(a). The presented unit cell consists of double layer dielectric substrates separated from each other with three parts of metallic elements. Each part of metallic elements is composed of rotated cross dipoles and meandered lines which are printed on the front surface of dielectric substrates. The first dielectric substrate is chosen as AD300A with a thickness h1 
and it has $\varepsilon_{\mathrm{r}}=3$ dielectric constant. The second one is chosen as AD600 dielectric substrate with h2 thickness and it has $\varepsilon_{\mathrm{r}}=6.15$ dielectric constant. Each of three parts of metallic elements contributes to the UWB response.

Metallic elements of each layer are shown in Fig. 1(b). Metallic elements "a" are printed on the front

\begin{tabular}{|c|c|}
\hline $\begin{array}{c}\text { Design } \\
\text { Parameters }\end{array}$ & $\begin{array}{c}\text { Dimensions } \\
{[\mathrm{mm}]}\end{array}$ \\
\hline Rin & 4.1 \\
\hline Rout & 4.5 \\
\hline w1 & 0.2 \\
\hline w2 & 0.2 \\
\hline w3 & 0.27 \\
\hline w4 & 0.32 \\
\hline D & 6.4 \\
\hline h1 & 1.524 \\
\hline h2 & 0.508 \\
\hline 11 & 1.34 \\
\hline K & 1.2 \\
\hline
\end{tabular}

Tab. 1. Design parameter of the first part of the metallic elements.
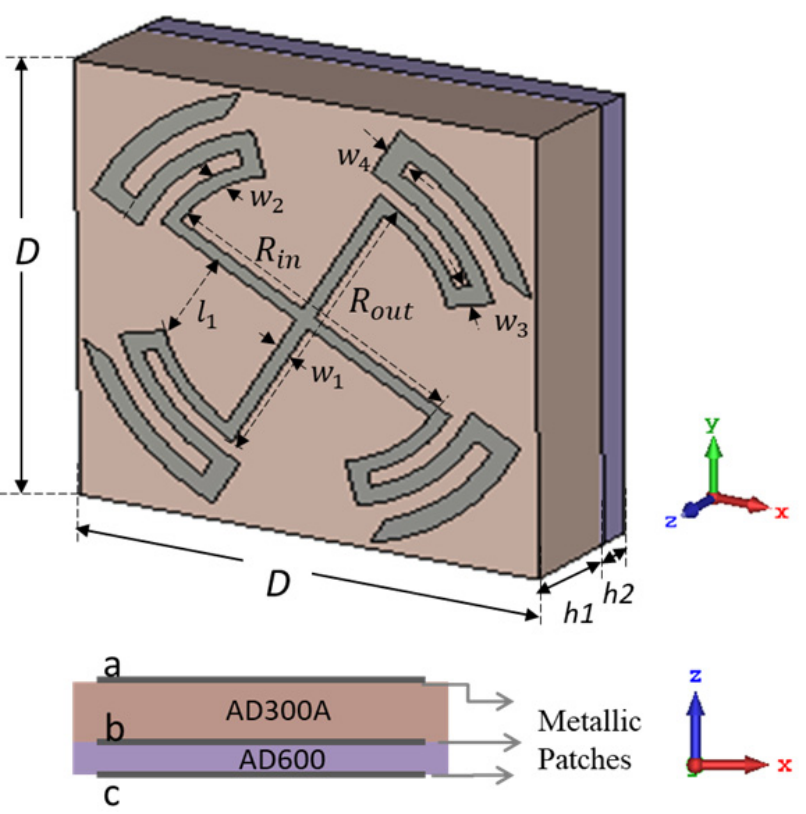

(a)

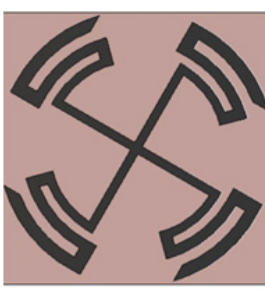

a
First layer

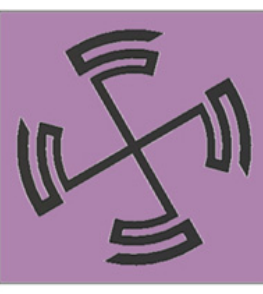

b

(b)

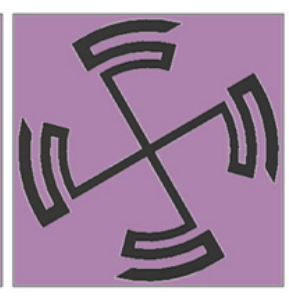

c
Fig. 1. (a) Geometry of the unit cell. (b) Metallic layer placements and their modification.

\begin{tabular}{|c|c|c|}
\hline & $\begin{array}{c}\text { Frequency } \\
{[\mathrm{GHz}]}\end{array}$ & $\begin{array}{c}\text { The Overall } \\
\text { Dimension }\end{array}$ \\
\hline Proposed & $2.98-10.86$ & $\begin{array}{c}0.064 \lambda \\
(6.4 \mathrm{~mm})\end{array}$ \\
\hline$[2]$ & $3.1-10.6$ & $\begin{array}{c}0.165 \lambda \\
(16.5 \mathrm{~mm})\end{array}$ \\
\hline$[4]$ & $3.02-11.79$ & $\begin{array}{c}0.151 \lambda \\
(15 \mathrm{~mm})\end{array}$ \\
\hline$[7]$ & $6.5-14$ & $\begin{array}{c}0.26 \lambda \\
(12 \mathrm{~mm})\end{array}$ \\
\hline$[8]$ & $5.5-19$ & $\begin{array}{c}0.238 \lambda \\
(13 \mathrm{~mm})\end{array}$ \\
\hline$[10]$ & $4.42-13$ & $\begin{array}{c}0.206 \lambda \\
(14 \mathrm{~mm})\end{array}$ \\
\hline$[11]$ & $4-14$ & $\begin{array}{c}0.18 \lambda \\
(14 \mathrm{~mm})\end{array}$ \\
\hline$[12]$ & $7.04-10.55$ & $\begin{array}{c}0.187 \lambda \\
(8 \mathrm{~mm})\end{array}$ \\
\hline
\end{tabular}

Tab. 2. Comparison of the dimensions.

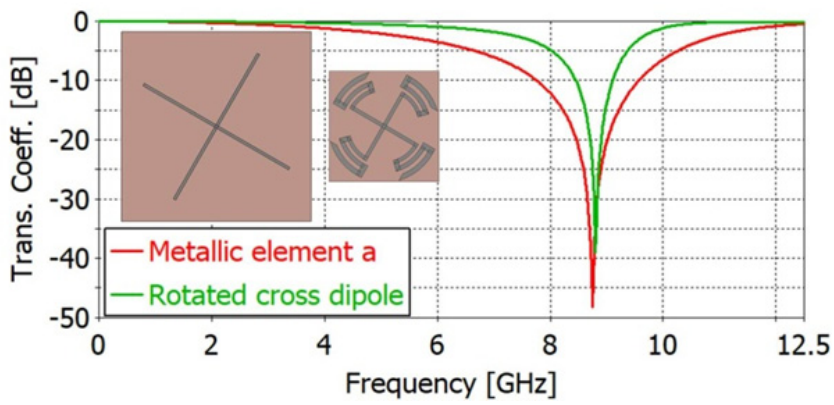

(a)

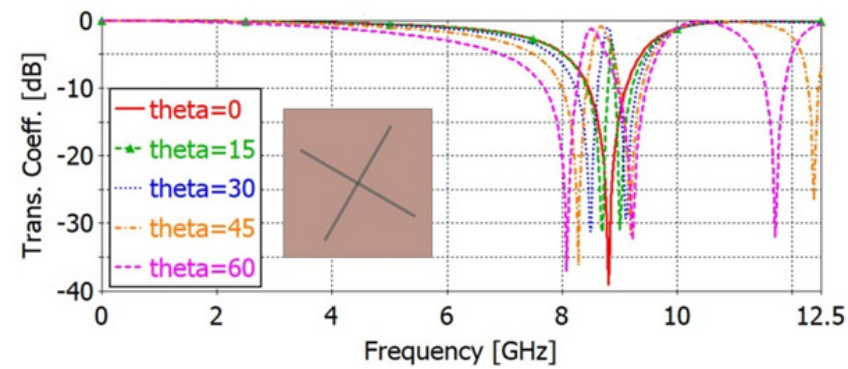

(b)

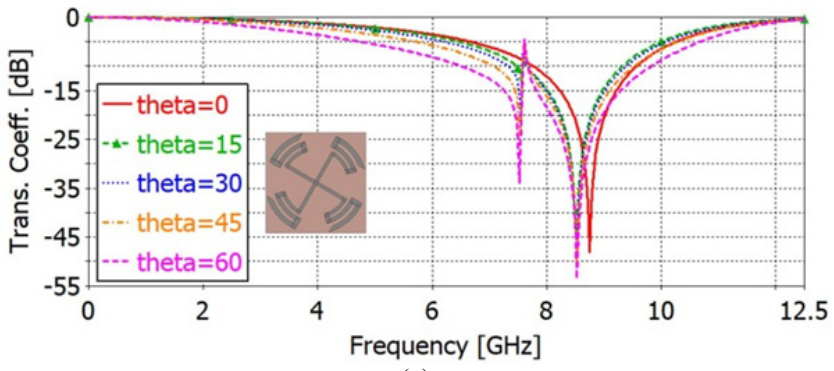

(c)

Fig. 2. Simulated transmission coefficients: (a) Comparison of the metallic element "a" and rotated cross dipole unit cell's transmissions under normal incidence. (b) Transmission under different incident angles for rotated cross dipole unit cell. (c) Transmission under different incident angles for the metallic element "a".

surface of the first dielectric substrate with the design parameters given in Tab. 1. Metallic elements which are called as "c" in Fig. 1(b), are obtained from scaling metallic element "a" with 0.95 and rotating by $60^{\circ}$ for the purpose of enlarging the operating frequencies. Metallic ele- 
ments "b" are obtained from scaling metallic element "c" by 0.9 and are settled on the second substrate as illustrated in Fig. 1(a). Also, w1 is excepted from these scaling processes. The unit cell is designed with the parameters given in Tab. 1 by using CST Microwave Studio. The overall dimensions of the unit cell in $\mathrm{x}$ and $\mathrm{y}$ directions are $\mathrm{D} \times \mathrm{D}$ $\mathrm{mm}$. The unit cell size for the lower cut off frequency equals to $0.064 \lambda \times 0.064 \lambda$, where $\lambda$ corresponds to free space wavelength.

The overall dimension of the presented unit cell is compared with other works reported in the literature and is given in Tab. 2. The unit cell dimension is calculated considering the lower cut-off frequency where $\lambda$ corresponds to free space wavelength. Adding meandered lines to the cross dipole is the simple structural modification which reduces the unit cell at the size. As seen in Tab. 2 the designed unit cell has the advantage with its miniaturized size.

When the metallic element "a" geometry which consists of rotated cross dipole and meandered lines is used instead of the rotated cross dipole, approximately the same transmission response is obtained with larger unit cell size $(14 \mathrm{~mm})$ when illuminated by a plane wave under normal incidence. Since the unit cell size is bigger than the proposed dimensions about $79.1 \%$, the angular sensitivity increases depending on the unit cell size when a unit cell is illuminated by a plane wave under various incident angles. Transmission characteristics for rotated cross dipole and the metallic element "a" are demonstrated in Fig. 2.

\section{Simulation and Measurement}

Simulation results of the designed unit cell for both TE and TM polarizations at normal incidence angle are shown in Fig. 3. As seen in Fig. 3, the proposed structure exhibits band-stop filter characteristic between $2.98 \mathrm{GHz}$ and $10.86 \mathrm{GHz}$ considering $-3 \mathrm{~dB}$ level. The transmission and reflection coefficients are computed by considering unit cell boundary with frequency domain solver using CST Microwave Studio.

The simulation results of transmission responses under the various incidence angles for TE polarization are illustrated in Fig. 4. Thus, the angularly stable transmission characteristics at different incident angles $\theta\left(0^{\circ}, 15^{\circ}, 30^{\circ}\right.$, $45^{\circ}$ and $60^{\circ}$ ) for TE polarization can be observed from Fig. 4 and the simulation results introduce that the unit cell

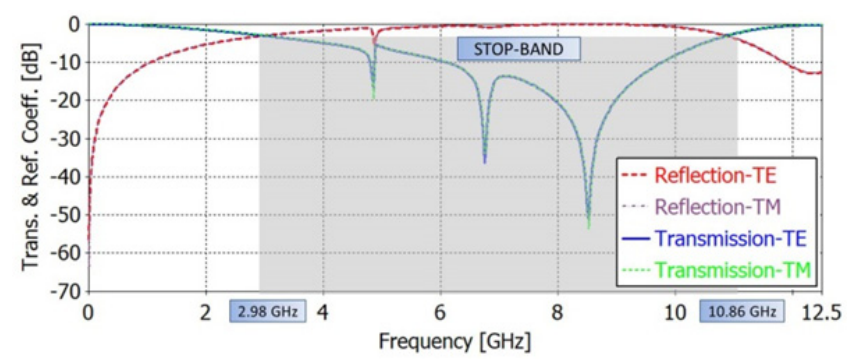

Fig. 3. Simulation results of transmission and reflection coefficients for TE and TM polarizations at normal incidence.

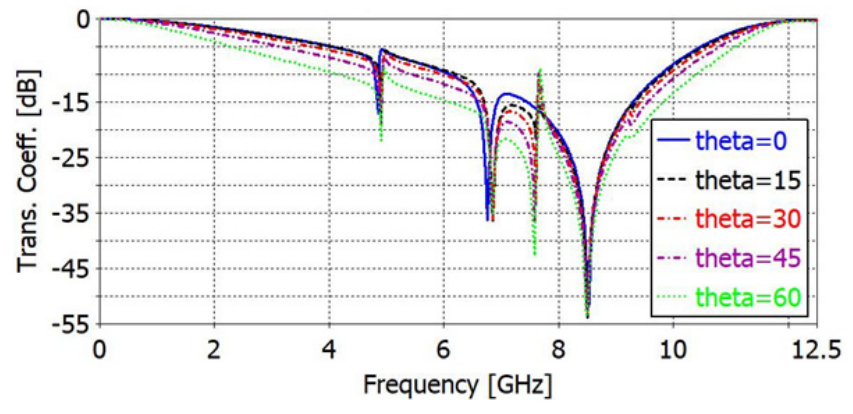

Fig. 4. Simulation results of transmission coefficient at different incidence angles for TE polarization.

\begin{tabular}{|c|c|c|}
\hline $\begin{array}{c}\text { Incidence Angle } \\
\text { (TE Polarization) }\end{array}$ & $\begin{array}{c}\text { Lower Cut-off } \\
\text { Frequency at }-3 \mathrm{~dB} \\
{[\mathrm{GHz}]}\end{array}$ & $\begin{array}{c}\text { Higher Cut-off } \\
\text { Frequency at-3 dB } \\
{[\mathrm{GHz}]}\end{array}$ \\
\hline $0^{\circ}$ & 2.98 & 10.86 \\
\hline $15^{\circ}$ & 2.92 & 10.95 \\
\hline $30^{\circ}$ & 2.65 & 11.03 \\
\hline $45^{\circ}$ & 2.2 & 11.17 \\
\hline $60^{\circ}$ & 1.58 & 11.39 \\
\hline
\end{tabular}

Tab. 3. Cut off frequencies of the transmission response at $-3 \mathrm{~dB}$ for different incidence angle for TE polarization.

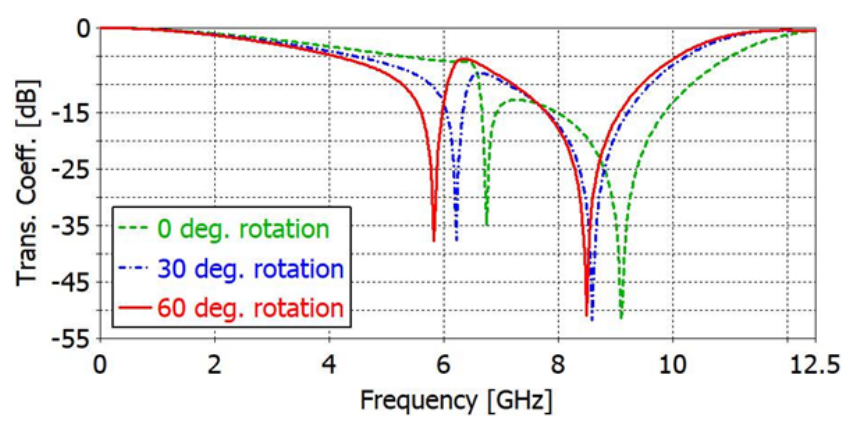

Fig. 5. Simulation results of transmission coefficient at normal incidence for the rotational variation of the metallic element "c".

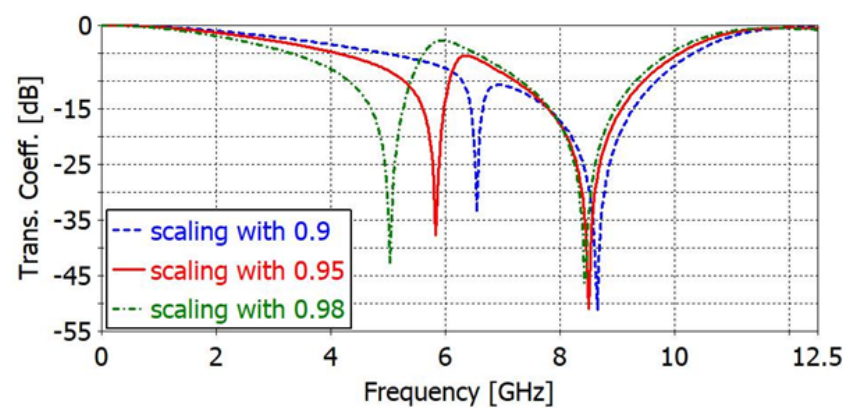

Fig. 6. Simulation results of transmission coefficient at normal incidence for the scaling variation of the metallic element "c".

has an angularly stable transmission characteristic due to its miniaturized size.

In Tab. 3 lower and higher cut-off frequencies at oblique incidence angles up to $60^{\circ}$ for TE polarization are given. According to the results represented in Fig. 4 and Tab. 3 it can be easily seen that the designed FSS comprises UWB range defined by FCC at each analyzed incidence angle value. 


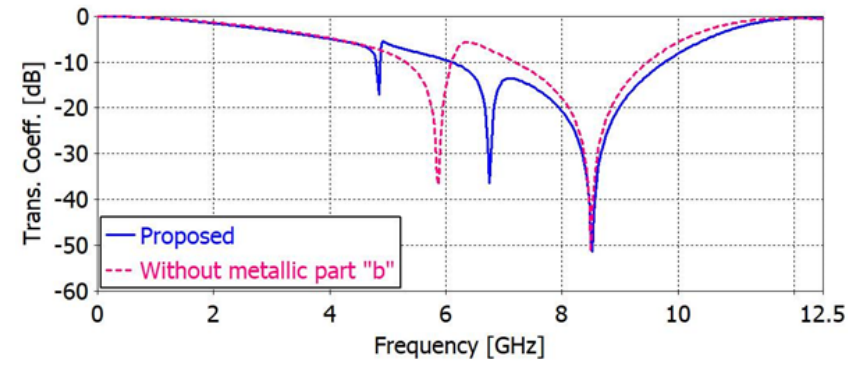

Fig. 7. Comparison of transmission coefficients at two design stages.

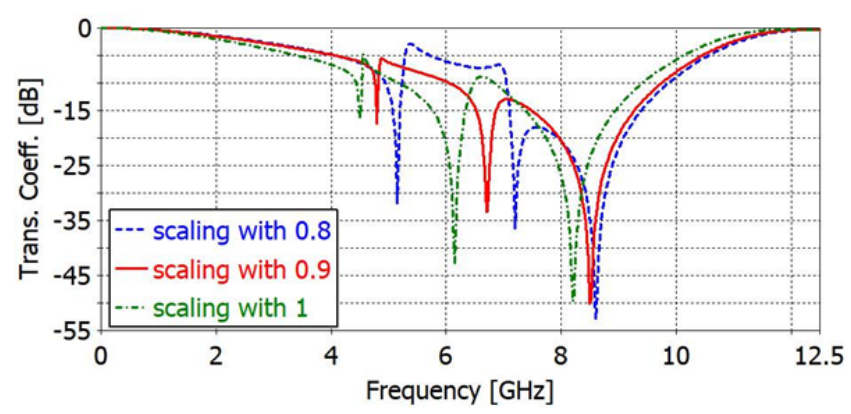

Fig. 8. Simulation results of transmission coefficient at normal incidence for the scaling variation of the metallic element "b".

During design procedure metallic element "c" is placed at the different rotational angles to obtain lower operational frequency under $3.1 \mathrm{GHz}$. As seen in Fig. 5, under the $-3 \mathrm{~dB}$ transmission level, the desired frequency is provided by $60^{\circ}$ settlement. After rotating process metallic element "c" needs to shrink to fit into the unit cell without affecting the operating frequency. The various scaling factors are tested as seen in Fig. 6.

During the design process, some structural studies are carried out in order to get a design covering the whole UWB frequency range. The trial design unit cell was not containing metallic element " $b$ ". The transmission characteristic of this design with two metallic parts does not provide FCC UWB standards with the $3.12-10.5 \mathrm{GHz}$ cut-off frequencies as seen in Fig. 7. So that the transmission characteristic given in Fig. 7 is obtained by adding to the third metallic element called " $b$ " to the structure of smaller size to influence the higher frequencies in the transmission response. By adding a smaller sized metallic element " $b$ " into the middle of two dielectric layers, the upper frequency band is enlarged. The parametric analysis is performed for different scaling ratios that caused the metallic element " $b$ " to enlarge the upper operational frequency at $-3 \mathrm{~dB}$ transmission level. The obtained transmission characteristics for various scaling factors are illustrated in Fig. 8. Thus, scaling metallic element "b" with 0.9 allows the whole structure to achieve FCC UWB standards with $2.98 \mathrm{GHz}-10.86 \mathrm{GHz}$ at $3 \mathrm{~dB}$.

Each two dielectric substrates with three parts of metallic elements contribute to UWB frequency response. These contributions are shown in Fig. 9 for each dielectric layer separately. The transmission characteristic of the first layer with metallic element "a" is enhanced by adding the

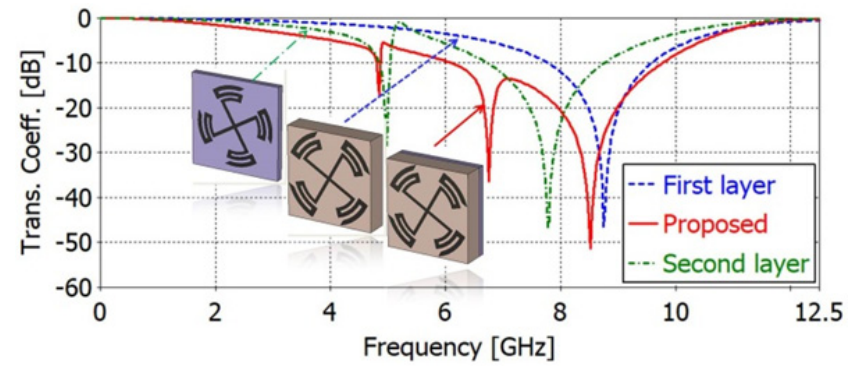

Fig. 9. Effects of each two layers of the unit cell.

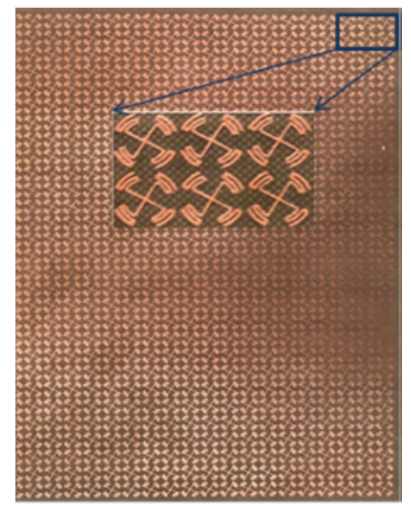

(a)

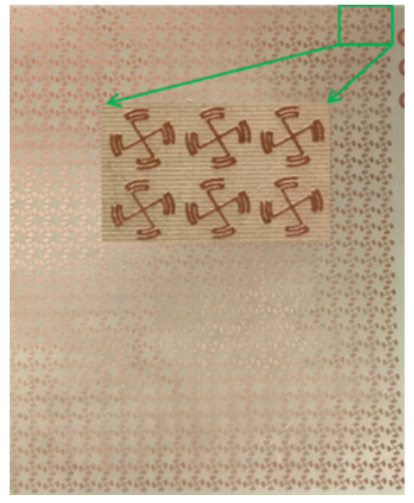

(b)

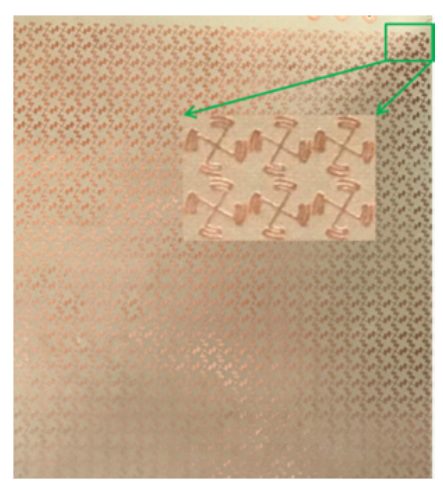

(c)

Fig. 10. Fabricated FSS prototype.

second layer with two parts of metallic elements " $b$ " and "c" on the opposite surfaces to the structure.

To verify the simulation results, the proposed FSS structure is fabricated and measured. The designed FSS prototype which is performed by numerical simulations is realized on an AD300A and AD600 substrates with the thickness of $1.524 \mathrm{~mm}$ and $0.508 \mathrm{~mm}$, respectively.

Figure 10 demonstrates the photo of the fabricated UWB FSS prototype. Each double layer FSS prototypes have approximately $210 \mathrm{~mm} \times 297 \mathrm{~mm}$ dimensions. The standard free space measurement technique was used to obtain the fabricated band-stop UWB FSS performance as shown in Fig. 11. The measurements are performed with transmitting and receiving identical broadband SMA waveguide horn antennas with nominal $11 \mathrm{~dB}$ gain and Rohde\& Schwarz ZVB 20 VNA (Vector Network Analyzer) with the low-loss coaxial cable. The aperture of used horn antennas is $244 \mathrm{~mm} \times 164 \mathrm{~mm}$ with the taper lengths of 


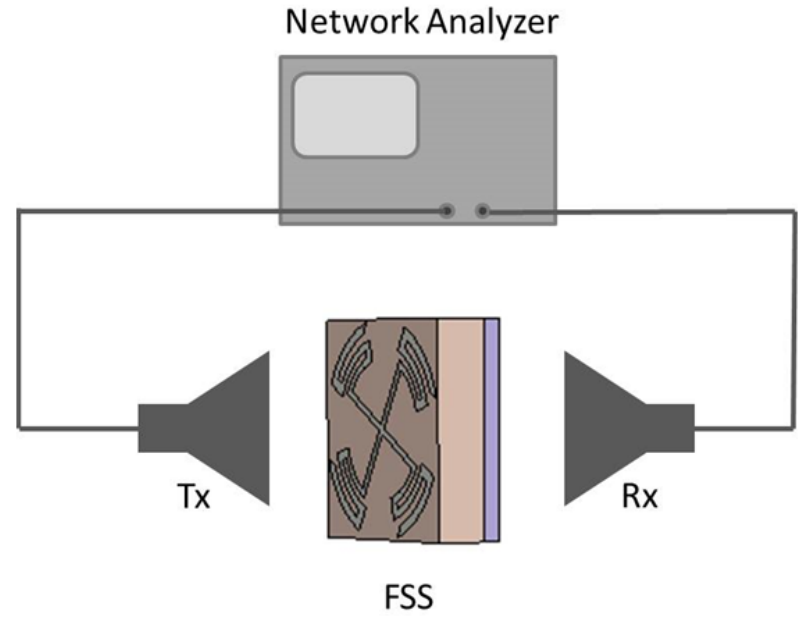

Fig. 11. Measurement setup.

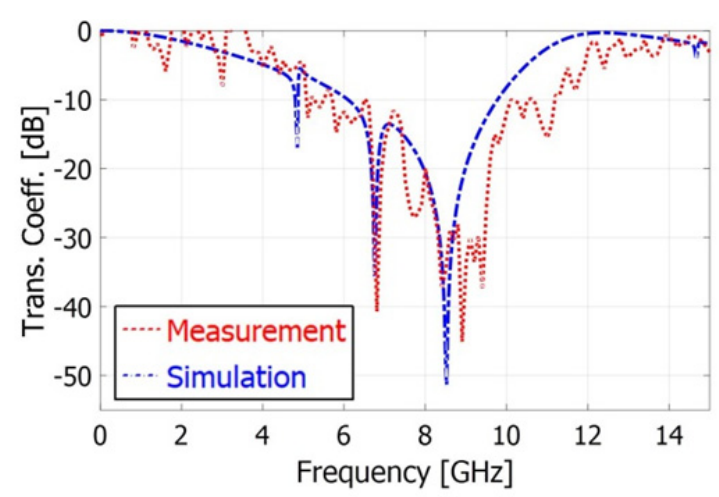

Fig. 12. Transmission response of simulation and measurement results.

$204 \mathrm{~mm}$. The receiving and transmitting antennas are positioned at the same height on the line of sight direction.

In Fig. 12 transmission characteristic of the simulation and measurement results of the proposed FSS under normal incidence for TE polarization is illustrated. A good agreement is obtained between the simulation and measurement results.

\section{Conclusion}

In this study, a novel FSS structure with angularly stable and polarization independent band-stop response is presented for UWB applications. The designed unit cell has band-stop UWB transmission response between $2.98 \mathrm{GHz}$ and $10.86 \mathrm{GHz}$ under $-3 \mathrm{~dB}$ transmission. Due to the miniaturized size of the unit cell, the proposed structure exhibits an angularly stable response to the oblique angles of incidence (up to $60^{\circ}$ ) for TE polarization. Although the structure is configured using two layers, the overall thickness of the unit cell is $0.02 \lambda$. Also, the dimension of the unit cell for lower cut-off frequency is $0.064 \lambda \times 0.064 \lambda$, where $\lambda$ corresponds to free-space wavelength. The designed unit cell is performed with CST Microwave Studio. The designed FSS was fabricated and measured to confirm the simulation results. Simulated and measured results have a good agreement.

\section{References}

[1] MUNK, B. A. Frequency Selective Surfaces: Theory and Design. New York: Wiley, 2000. ISBN: 978-0-471-37047-5

[2] YAHYA, R., NAKAMURA A., ITAMI, M. 3D UWB band-pass frequency selective surface. In IEEE International Symposium Antennas and Propagation (APSURSI). Fajardo (Puerto Rico), 2016, p. 959-960. DOI: 10.1109/APS.2016.7696188

[3] HABIB, S., KIANI, G. I., BUTT, M. F. U. An efficient UWB FSS for electromagnetic shielding. In International Conference on Electromagnetics in Advanced Applications (ICEAA). Verona (Italy), 2017, p. 1543-1546. DOI: 10.1109/ICEAA.2017.8065578

[4] KOCAKAYA, A., ÇAKIR, G., DIKMEN, C. A novel single layer frequency selective surface design for ultra-wide band antenna gain enhancement. In 10th International Conference on Electrical and Electronics Engineering (ELECO). Bursa (Turkey), 2017, p. 1075-1078.

[5] UNALDI, S., BODUR H., CIMEN, S., et al. A novel dual-band FSS reflector for RCS reduction. In International Conference on Engineering and Natural Sciences (ICENS 2016). Sarajevo (Bosna), 2016, p. 752-756. ISBN: 978-605-83575-1-8

[6] FEDERAL COMMUNICATIONS COMMISSION. First Report and Order, Revision of Part 15 of the Commission's Rules Regarding Ultra-Wideband Transmission Systems, ET Docket 98153, FCC 02-48, Feb. 2002.

[7] SOHAIL, I., RANGA, Y., MATEKOVITS, L., et al. A low-profile single-layer UWB polarization stable FSS for electromagnetic shielding applications. In International Workshop on Antenna Technology (iWAT). Sydney (Australia), 2014, p. 220-223. DOI: 10.1109/IWAT.2014.6958643

[8] LIU, L., LI, H., JIN, Z., CAO, Q., et al. Design of FSS-based UWB absorber using multilayer modified circular ring. In International Applied Computational Electromagnetics Society Symposium (ACES). Suzhou (China), 2017. ISBN: 978-0-99600785-6

[9] GURGEL DA SILVA SEGUNDO, F. C., PEREIRA DE SIQUEIRA CAMPOS, A. L. P., GOMEZ NETO, A. A design for ultrawide band frequency selective surface. Journal of Microwaves, Optoelectronics and Electromagnetic Applications, 2013, vol. 12, no. 2, p. 398-409. DOI: 10.1590/S217910742013000200012

[10] TAHIR, F. A., ARSHAD, T., ULLAH, S., et al. A novel FSS for gain enhancement of printed antennas in UWB frequency spectrum. Microwave and Optical Technology Letters, 2017, vol. 59, no. 10, p. 2698-2704. DOI: 10.1002/mop.30789

[11] SIVASAMY, R., MOORTHY, B., KANAGASABAI, M., et al. Polarization-independent single-layer ultra-wideband frequencyselective surface. International Journal of Microwave and Wireless Technologies, vol. 9, no. 1, p. 93-97. DOI: $10.1017 / \mathrm{S} 1759078715001439$

[12] BAISAKHIYA, S., SIVASAMY R., KANAGASABAI, M., et al. Novel compact UWB frequency selective surface for angular and polarization independent operation. Progress In Electromagnetics Research Letters, 2013, vol. 40, p. 71-79. DOI: 10.2528/PIERL13022707

[13] KOCAKAYA, A., ÇAKIR G. A novel angular independent higher order band-stop frequency selective surface for X-band applications. IET Microwaves, Antennas and Propagation, 2018, vol. 12, p. 15-22. DOI: 10.1049/iet-map.2016.0907

\section{About the Authors ...}

Sibel ÜNALDI received her M.Sc. from the Y1ldı Technical University, İstanbul, Turkey in 2015. She is a Ph.D. 
student at Sakarya University, Sakarya, Turkey. Her research interests include frequency selective surfaces, reflectarray antennas, RCS reduction.

Nigar Berna TEŞNELI (corresponding author) received the B.S., M.S., and Ph.D. degrees in Physics Engineering from the University of Hacettepe, Ankara, Turkey, in 1998, 2000, and 2005, respectively. She worked as a Research and Teaching Assistant at the Department of Physics Engineering, University of Hacettepe, Ankara from1999 to 2005. In 2003, she was a Research Engineer with the Nanomaterial Engineering Group, University of Sheffield, Sheffield, U.K., where she was involved in thin film studies. Since 2006, she has been working as an Assistant Professor with the Department of Electrical and Electronics Engineering, Faculty of Engineering, University of Sakarya, Sakarya, Turkey. Her research interests include electromagnetic field theory, wave propagation, numerical methods, antenna design, metamaterials, electromagnetic bandgap structures, frequency selective surfaces electromagnetic measurements, electromagnetic compatibility, health effects of EM fields and thin film technologies.

Sibel ÇIMMEN (S'08-M'13) was born in Çanakkale, Turkey, in 1980. She received the B.S., M.S., and Ph.D. degrees in Electronics and Communication Engineering from Kocaeli University (KOU), Kocaeli, Turkey, in 2002, 2005, and 2009, respectively. From 2005 to 2009, she was a Research Assistant with the Microwave and Antennas Laboratory. Currently, she is an Associate Professor with the Electronics and Communication Engineering Department, KOU. Her research interests include numerical methods for planar structures, metamaterials, frequency selective surfaces, reflectarray antennas and design of UWB antennas and microstrip filters. 